\title{
Pearl without Oyster; Pregnancy without Uterus!
}

\section{Delphine T. Rose*, Rajarajeswari R.}

Department of Obstetrics \& Gynaecology, Thanjavur Medical College, Thanjavur, Tamil Nadu, India

Received: 23 January 2016

Revised: 15 February 2016

Accepted: 17 February 2016

\author{
*Correspondence: \\ Dr. Delphine T. Rose, \\ E-mail: drdelphinerose@gmail.com
}

Copyright: () the author(s), publisher and licensee Medip Academy. This is an open-access article distributed under the terms of the Creative Commons Attribution Non-Commercial License, which permits unrestricted non-commercial use, distribution, and reproduction in any medium, provided the original work is properly cited.

\begin{abstract}
Is pregnancy possible after removal of the uterus? Pregnancy is virtually never thought of after hysterectomy. Although rare it is still possible for a reproductive age group woman to conceive after hysterectomy when the tubes and ovaries are left behind. A sperm enter through a fistulous tract in the vaginal vault, fertilize the ovum, implant in the tube and grow. The end result can be catastrophic, if diagnosed late. Fortunately such post-hysterectomy ruptured ectopic gestation is a very rare event; so far only 72 cases have been reported in literature. Here we report a case of ruptured tubal gestation in a 25year old patient after four years of peripartum hysterectomy, who had a successful outcome because of timely diagnosis and early treatment.
\end{abstract}

Keywords: Pregnancy, Hysterectomy, Ectopic gestation

\section{INTRODUCTION}

An ectopic pregnancy after a hysterectomy is a rare event, with about 72 reported cases so far, since it was first identified by Wendeler. ${ }^{1}$ It can present soon after hysterectomy or several years later. Early ectopic pregnancies $(56 \%)$ are more common than late ectopic pregnancies $(44 \%){ }^{2}$ Ectopic pregnancy can occur after any type of hysterectomy and the patient may present with acute abdomen. ${ }^{1}$ These patients often land up in medical or surgical departments leading on to delay in making a diagnosis. Such delay can end in rupture of ectopic pregnancy and can be potentially life-threatening.

\section{CASE REPORT}

A 25 year-old Mrs. J, referred from a private hospital as a case of acute abdomen with ascites, was admitted in our labor ward casualty with history of lower abdominal pain, giddiness and vomiting for 4 days. Patient had undergone peripartum subtotal hysterectomy for atonic postpartum hemorrhage four years back. On examination patient was in a state of shock with cold and clammy extremities, restlessness, pallor, tachypnea with an unrecordable pulse and blood pressure.
Abdominal examination revealed distended lower abdomen with minimal tenderness but no guarding or rigidity. On vaginal examination, fullness of vaginal vault was noted. Hemoglobin and hematocrit were $4.8 \mathrm{~g} \%$ and $22 \%$ respectively. Transvaginal ultrasonography revealed a complex heterogeneous pelvic mass of size $7 X 5 \mathrm{~cm}$, absent uterus with free fluid.

Paracentesis revealed dark altered blood. Differential diagnosis of ?ruptured tubo-ovarian abscess, ?ruptured ovarian cyst, ?appendicular perforation was thought of.

Initial resuscitation was done and the patient was taken up for emergency exploratory laparotomy. On opening the abdomen, there was haemoperitoneum of 1 litre and blood clots of about 200 grams were evacuated. A friable mass was found in the right adnexal region and the same removed. Tube and ovary were not seen separately on that side. Opposite tube and ovary were found to be normal. Specimen was sent for histopathology.

Four units of blood transfusion were given totally. Urine pregnancy test done in the emergency theatre was positive. Postoperative period was uneventful and the patient was discharged on $7^{\text {th }}$ day. Histopathological 
report was consistent with tubal ectopic gestation.
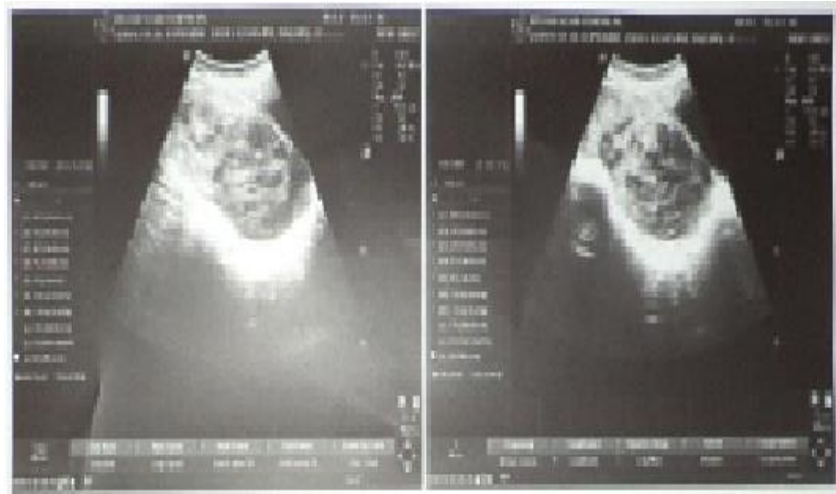

Figure 1: USG shows heterogeneous mass in the pelvis.

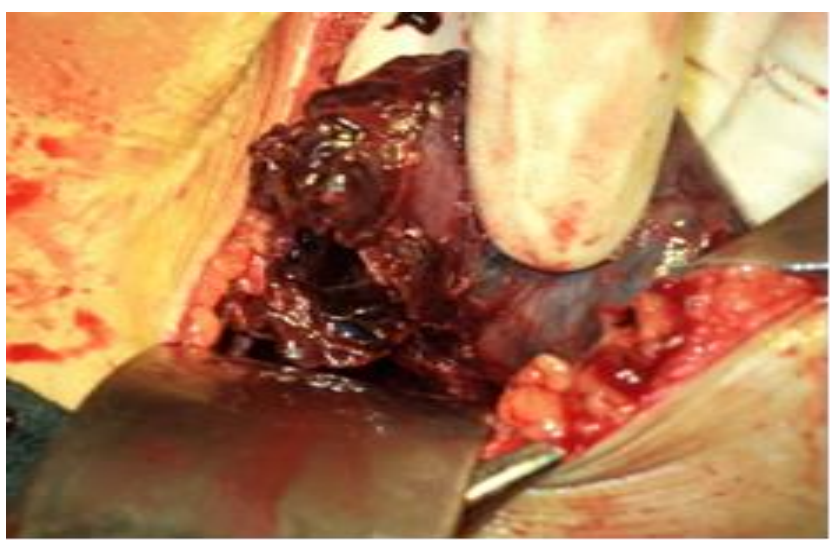

Figure 2: Friable mass in the pelvis as seen in laparotomy.

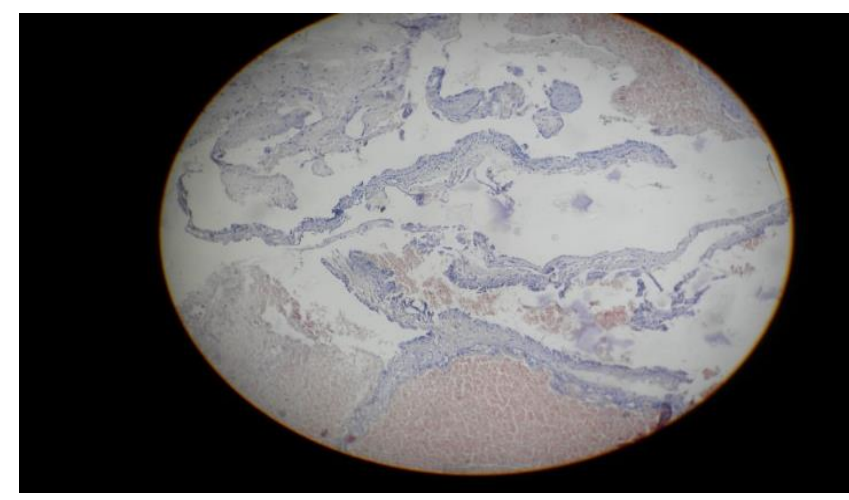

Figure 3: Microscopic picture shows presence of tubal smooth muscle hyperplasia and villi consistent with ectopic gestation.

\section{DISCUSSION}

Ectopic pregnancy, which is the implantation of the blastocyst outside the uterus, is a common cause of mortality in early pregnancy. It occurs in $2 \%$ of all reported pregnancies. ${ }^{3}$ Although fallopian tube is the commonest site of implantation $(97 \%)$, there are other rare sites like the cervix, the ovary and the caesarean scar. But the most unusual form of ectopic pregnancy is the one that occurs in the absence of uterus, i.e. after hysterectomy. The diagnosis and treatment of these posthysterectomy ectopic pregnancies present both diagnostic and therapeutic dilemmas. Vaginal bleeding following a short period of amenorrhea which is considered as a classical symptom of ectopic pregnancies have no significance here and the patients usually present with vague and non-specific symptoms like lower abdominal pain, vomiting and giddiness, as in our case. This is the cause for the delay in diagnosis and treatment.

Early ectopic pregnancy occurs within few weeks to 1 month after hysterectomy. This is due to entrapment of fertilized ovum in the fallopian tube at the time of hysterectomy. ${ }^{2}$ Whereas late ectopic occurs from 4 months to 12 years, which is mainly due to access of spermatozoa to an ovulated ovum through a fistulous tract between the vagina and the adnexa in peritoneal cavity. $^{2}$

Such fistulisation in turn can be favoured by the presence of haematomas or pelvic infections in the region of the vaginal vault. Another mechanism that could favour ectopic pregnancy is Fallopian tube prolapse into the vagina, thereby creating a vaginal-tubal communication that is more common following vaginal hysterectomies ${ }^{4}$. Some authors report that the practise of tying the tuboovarian pedicle to the vaginal vault during vaginal hysterectomies is the reason for the increase incidence of ectopic pregnancies.

In subtotal hysterectomy, chance of a fistulous tract formation may be increased by leaving a remnant of cervix or the epithelialization of much larger vaginal cuff due to cervical dilatation at the time of hysterectomy, as in our case. The presence of a fistulous tract can be diagnosed by fistulography or by MRI. ${ }^{6,7}$

Laparoscopic hysterectomy is currently the most popular method of hysterectomy in young women in whom tubes and ovaries are left behind. There is no report in the literature that laparoscopic hysterectomies increase the risk of ectopic pregnancies in future. ${ }^{2}$

Early presentations could be prevented with adequate contraception before hysterectomy or by avoiding surgery in the luteal phase. ${ }^{8}$ In late presentations, the frequency of ectopic pregnancies could be reduced by doing salpingectomy along with hysterectomy, careful vaginal cuff sealing, keeping the adnexal areas at a distance, and covering with peritoneum. Avoiding pelvic haematomas and infections could reduce the incidence of fistular tracts. Surgery is the treatment of choice in all cases. Medical management is not possible as the diagnosis is usually made only after the rupture and it is not acceptable as it does not avoid future recurrences. ${ }^{9}$ Surgery can be laparoscopic or laparotomy. If there is a fistulous tract it should be closed. ${ }^{10}$ 


\section{CONCLUSIONS}

Studies show that mortality rate of ectopic pregnancy following hysterectomy is more than ectopic pregnancy with intact uterus. The symptoms can be non-specific. It is imperative to maintain high index of suspicion to diagnose ectopic pregnancy in post-hysterectomy women of child bearing age presenting with acute abdominal pain, if the ovaries are in situ. A simple urine pregnancy test which is readily available and inexpensive can clinch the diagnosis.

Informed consent was obtained from the patient.

Funding: No funding sources

Conflict of interest: None declared

Ethical approval: Not required

\section{REFERENCES}

1. Flystra Dl. Ectopic pregnancy after Hysterectomy; a review and insight into etiology and prevention, fertility and sterility. 2010;94(2):431-5.

2. Bansal S, Payal Y. Ectopic Pregnancy Following Laparoscopic-Assisted Vaginal Hysterectomy in Tubectomised Women. J Obstet Gynaecol India. 2014;64(Suppl 1):47-9.

3. Early pregnancy loss and ectopic pregnancy. In:
Berek and Novak's gynaecology. 15th ed; Lippincott Williams and Wilkins; 2012:622.

4. Pasic R, Scobec J, Tolar B. Ectopic pregnancy months after lap supracervical Hysterectomy. Jr of American Association of gynecologist laparoscopists 2004;11:94-5.

5. Sheth SS. Vaginal hysterectomy. Best Pract Res Clin Obstet Gynecol. 2005;19(3):307-32.

6. Brown WD, Burrows L, Todd CS. Ectopic pregnancy after caesarean Hysterectomy. Obst and Gynac, 2002.

7. Isaacs JD, Casarc CD, Cowan BD. Ectopic pregnancy following hysterectomy. Obst \& Gynae. 1996;88(732).

8. Bansal S, Saini M, Harsh M, Amrita K, Chatuverdi J. Is ectopic pregnancy possible after hysterectomy? Fertil Steril. 2010;94(1):350.e5-7.

9. Allen B, East M: ectopic pregnancy following Lap assisted vaginal Hysterectomy. Australian and NewZealand journal of Obstetrics and gynecology. 1998;38(1):112-3.

10. Babikian S, Thoma DC, Berkey BD. Ruptured ectopic pregnancy after 3 years of supracervical hysterectomy.J Ultrasound Med. 2008;27(7):108790.

Cite this article as: Delphine Ts, Rajarajeswari R.

Pearl without Oyster; Pregnancy without Uterus! Int J Reprod Contracept Obstet Gynecol 2016;5:937-9. 